Proc. Indian Acad. Sci. (Earth Planet. Sci.), Vol. 91, No. 1, March 1982, pp. 1-13. (C) Printed in India.

\title{
On the seismic structure of Indian upper-mantle regions
}

\author{
AVADH RAM and OM PRAKASH SINGH \\ Department of Geophysics, Banaras Hindu University, Varanasi 221 005, India
}

MS received 2 April 1981; revised 11 December 1981.

\begin{abstract}
Several velocity models on upper mantle regions of the world have been postulated during the last two decades. There has been a broad agreement amongst seismologists that upper mantle has got two transition zones, though the models differ in detail. These zones have been found to occur around ' $400 \mathrm{~km}^{\prime}$ ' and ' $650 \mathrm{~km}$ ' depth ranges with varying thicknesses of the zones. A limited number of such studies have been made on the upper mantle structure of the Indian subcontinent. High positive velocity gradients were reported to exist around the above depth range. Evidence for lateral heterogeneities has also been found. We address some problems like refinement of Indian upper mantle velocity models specially after considering the effect of scattering and attenuation on the short period $P$-waves. The study of proper positioning of the cusps of the travel-time branches and their extension is essential as well. In our opinion, analysis of such problems would help in the better understanding of the nature of propagation of seismic waves and mechanism of earthquakes. Complexity of seismic signatures observed is another major problem and may also be taken into consideration.
\end{abstract}

Keywords. Upper mantle; velocity models.

\section{Introduction}

Importance of mechanism of earthquakes and their source parameters in the light of earthquake prediction, movement of the lithospheric plates and different tectonic processes have necessitated the study of upper mantle in detail and its regional variation of the seismic structure in particular. A large number of upper mantle velocity models for different regions of the world have been postulated during the last fifteen years or so from $P$-wave travel time observations and slowness data. Although, these models differ from each other in detail, most of them have shown common evidence for discontinuities or large positive velocity gradients near the ' $400 \mathrm{~km}$ ' and ' $650 \mathrm{~km}$ ' depth ranges. A knowledge of the distribution of seismic velocity with depth plays an important role in the distribution of other physical properties of the earth such as density, elastic constants and chemical composition. Thus, any refinement that can be made for seismic velocity models is very important. The Indian subcontinent is of particular interest to Geoscientists as it has moved northward and collided with the Asian subcontinent. Himalayan and other mountain ranges in the north and mid-oceanic ridges to the south in the Indian ocean, all show that the upper mantle structure around the Indian Peninsula must have beterogeneous composition.

A number of studies on upper mantle seismic structure of Indian regions have been carried out. Lukk and Nersesov (LN) 1965, Tandon (T) (1967) and Kaila et al (KKN) (1969) gave the upper mantle velocity models for the Hindukush region. A critical 
analysis of these $P$-wave velocity models reveals that they differ with each other in detail, thus indicating the variations in the seismic structure of the upper mantle regions. It can be pointed out that these differences include the uncertainties in observations and methods of analysis of the data. However, due corrections have been applied in all such cases. Most models are derived on the basis of statistical analysis. The model KRN (1968) (Kaila et al 1968) is for northern regions. Models B1 and B2 (1974) (Bhattacharya 1974) are for the Central Peninsula and Western Ghats of the Indian subcontinent respectively. Models RM1 and RM4 (1977) are for the continental regions whereas models RM2 and RM3 (1977) are for the Indian oceanic regions derived by Ram and Mereu. An evidence for the ' $400 \mathrm{~km}$ ' and ' $650 \mathrm{~km}$ ' discontinuities was found in most of the models with varying thicknesses of the transition zones. The location of some regions, World wide standardised seismograph networks (WWSSN) and the Gauribidanur seismic array (GBA) are shown in figure 1. A critical review of the above models is presented and viable areas of future research are outlined.

\section{Velocity structure of the Indian upper-mantle regions}

Very few investigations on the seismic structure of the Indian upper mantle reigons have been carried out in the past. Most of these studies have employed conventional methods for the analysis of earthquake data except the one where seismic array data

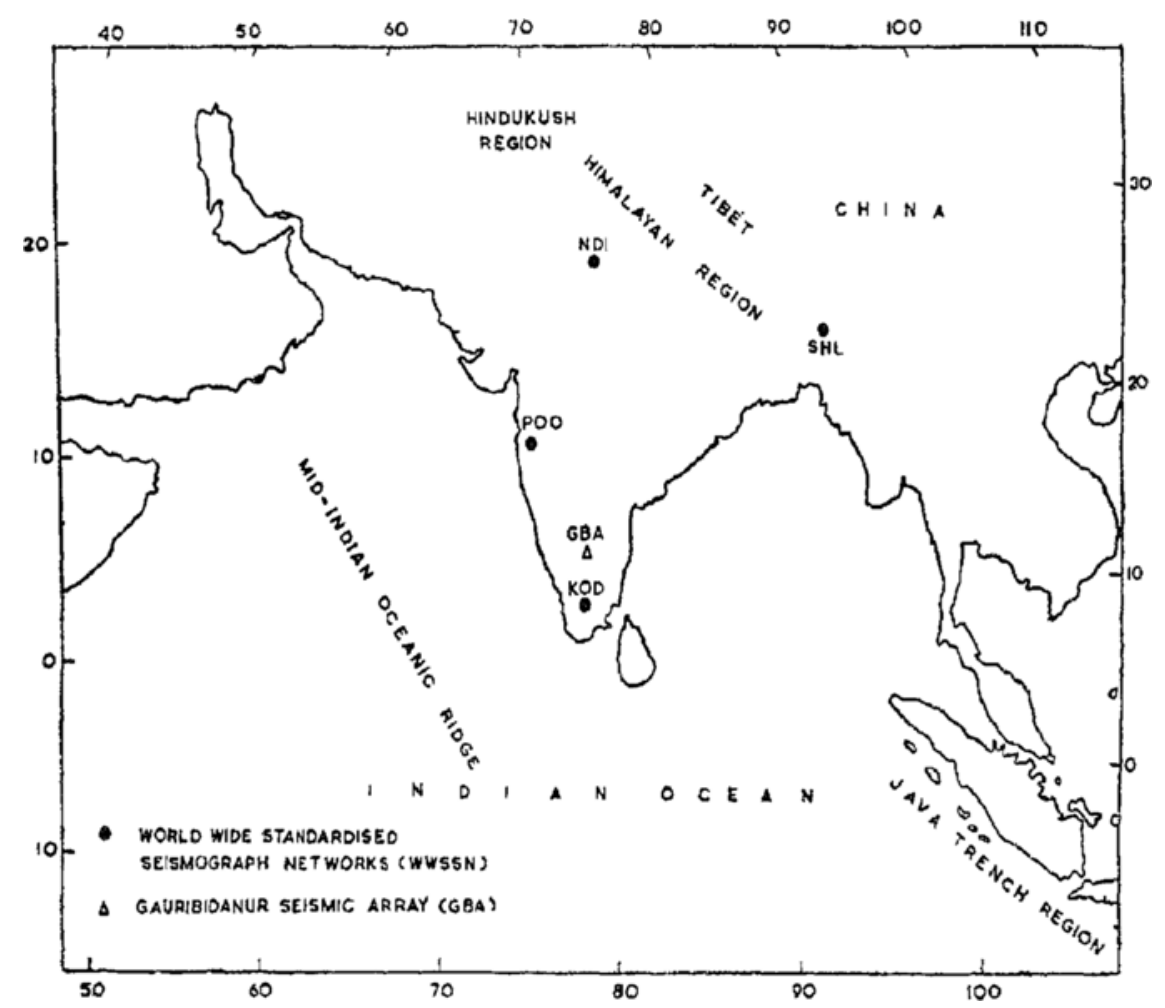

Figure 1. Location of few regions, World Wide Standardised Seismograph Network (WWSSN) stations and the Gauribidanur Seismic Array (GBA). 
was used and the slowness and apparent azimuths of the incoming $P$-waves were determined automatically using an adaptive processing technique. Various velocity models for $P$-waves are explained in the following sections.

\subsection{Model LN (1965)}

A velocity model LN (1965) by Lukk and Nersesov (1965) for the Hindukush region (figure $2 \mathrm{~A}$ ) shows considerably higher $P$-wave velocity as compared to those found by other workers for the same region. This model has a number of velocity discontinuities up to a depth of $240 \mathrm{~km}$. A low velocity layer in the depth range 110$150 \mathrm{~km}$ has also been reported by them. A sudden jump in the $P$-wave velocity in this model near a depth of $200 \mathrm{~km}$ was also found. Lukk and Nersesov (1965) have claimed an accuracy of \pm 0.1 to $0.15 \mathrm{~km} / \mathrm{sec}$ in the velocity determination to a depth of $240 \mathrm{~km}$.
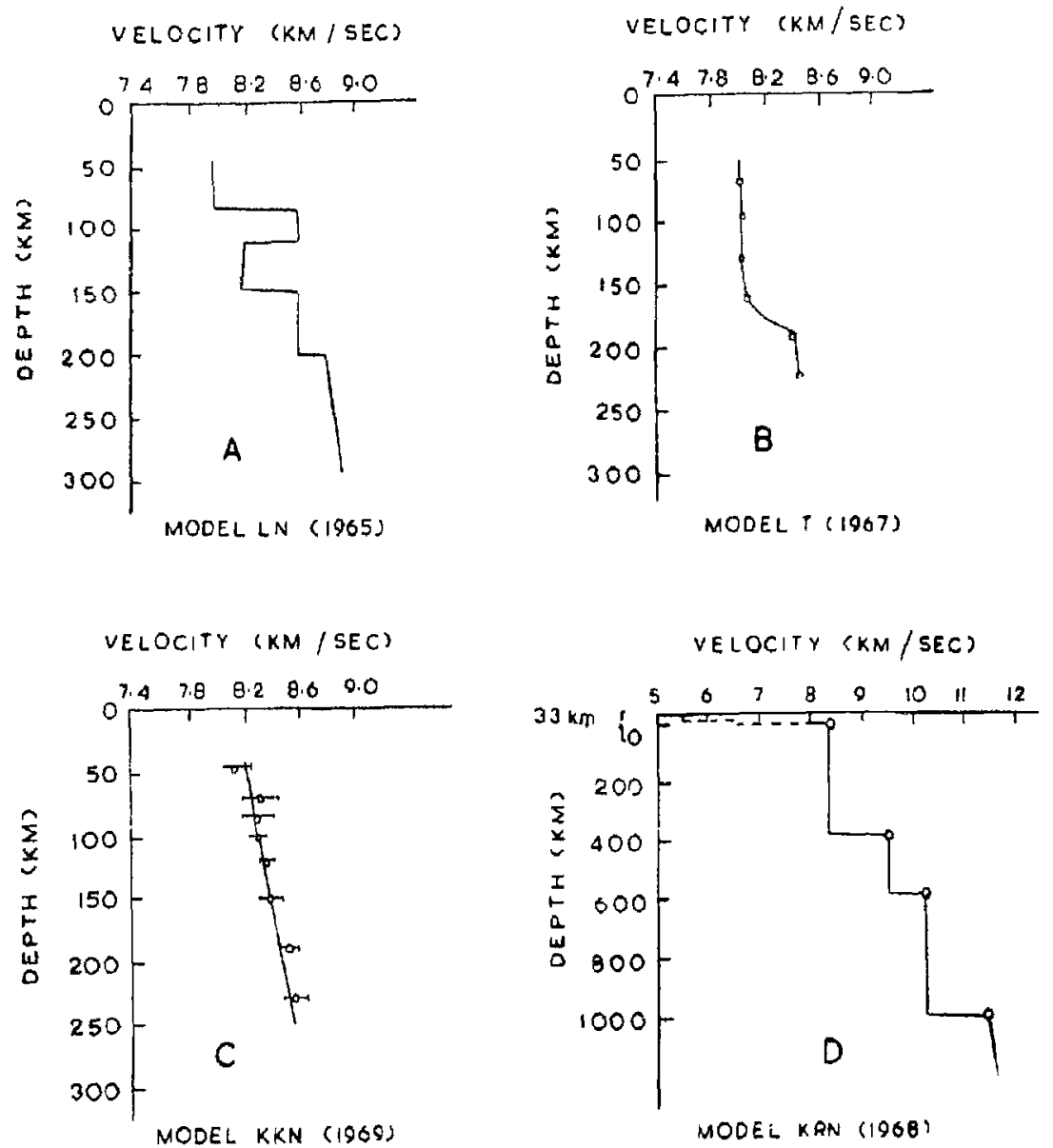

Figure 2. Upper mantle velocity models: (A) Model LN (1965), (B) Model T (1967), (C) Model KKN (1969) and (D) Model KRN (1968). Models A, B and C are for Hindukush region whereas model $D$ is for northern regions of Indian subcontinent. 


\subsection{Model T (1967)}

Tandon (1967) had derived seismic velocity models using over fifty earthquakes occurring at different depths in the Hindukush focal region and recorded at WwssN stations existing close to the Hindukush source region. This data was taken from the International Seismological Summaries (Iss) during the period 1949-1958 and earthquake parameters were used as such without any modification. Gutenberg's method was applied to determine seismic velocities in the uppermost mantle of the Hindukush region. A $P$-wave velocity model $\mathrm{T}(1967)$ is shown in figure $2 \mathrm{~B}$ and variation of the velocity with depth in table 1 . The seismic velocity for $P$-waves is almost constant $(8.0 \mathrm{~km} / \mathrm{sec})$ between $65-160 \mathrm{~km}$ depth range. A steep rise in this velocity after this depth range has been found up to $200 \mathrm{~km}$ depth. This indicates the presence of positive high velocity gradient between $160-200 \mathrm{~km}$ depth range. Below $200 \mathrm{~km}$ the value becomes almost normal. Tandon (1967) found the low velocity layer for $S$-waves at a depth of about $160 \mathrm{~km}$. However, no evidence for this layer in the case of $P$-wave velocity was reported by bim for this region.

\subsection{Model KKN (1969)}

A $P$-wave velocity model was derived by Kaila et al (1969) for Hindukush region using travel times of 28 deep focus earthquakes obtained from iss for the period 1959-1961. They applied an analytical technique, given by Kaila (1969), for determining the seismic wave velocity. The velocity model KKN (1969) is illustrated in figure $2 \mathrm{C}$ and table 2 shows the distribution of $P$-wave velocity with depth for this

Table 1. P-wave velocity distribution with depth for model $\mathrm{T}$ (1967).

\begin{tabular}{cc}
\hline $\begin{array}{c}\text { Depth/Radius } \\
(h / R)\end{array}$ & $\begin{array}{c}P \text {-wave velocity } \\
(\mathbf{k m} / \mathrm{sec})\end{array}$ \\
\hline 0.005 & 8.01 \\
0.01 & 8.03 \\
0.015 & 8.02 \\
0.02 & 8.07 \\
0.025 & 8.40 \\
0.030 & 8.45 \\
\hline
\end{tabular}

Table 2. $P$-wave velocity distribution with depth for model kxN (1969)

\begin{tabular}{cc}
\hline $\begin{array}{c}\text { Depth } \\
(\mathrm{km})\end{array}$ & $\begin{array}{c}P \text {-wave velocity } \\
(\mathrm{km} / \mathrm{sec})\end{array}$ \\
\hline 45 & $8.14 \pm 0.11$ \\
70 & $8.32 \pm 0.14$ \\
85 & $8.29 \pm 0.11$ \\
100 & $8.30 \pm 0.07$ \\
120 & $8.37 \pm 0.07$ \\
150 & $8.39 \pm 0.08$ \\
190 & $8.53 \pm 0.06$ \\
210 & $8.35 \pm 0.08$ \\
230 & $8.57 \pm 0.09$ \\
\hline
\end{tabular}


model. The model shows a least square fit for the velocity variation. A continuous linear increase (from $8.21-8.52 \mathrm{~km} / \mathrm{sec}$ ) has been found between depth range $45-230$ $\mathrm{km}$. This value is higher than that for other regions of the earth. Kaila et al (1959) did not confirm either the presence or absence of a low velocity model which shows a linear increase in the velocity between $85-230 \mathrm{~km}$ depth range.

\subsection{Models KRN (1968)}

Kaila et al (1968) statistically analysed the $P$-wave travel times of 39 shallow focus earthquakes besides three nuclear explosions occurring in the Himalayas, Tibet, China and USSR recorded at Indian seismological observatories during the period 1953-1965. Their velocity model KRN (1968) is shown in figure 2D and the variation of $P$-wave velocity with depth is given in table 3. These velocities were found by the method of weighting observations. Complete travel time curve has been represented by four straight line segments for $\Delta=2^{\circ}$ to $50^{\circ}$ indicating abrupt velocity changes around $19^{\circ}, 22^{\circ}$ and $33^{\circ}$. Thus, they found three velocity discontinuities at depths, below the crust, of $380 \pm 20,580 \pm 50$ and $1000 \pm 120 \mathrm{~km}$ with $P$-wave velocities below these discontinuities as $9.47 \pm 0.6,10.15+0.07$ and $11.40 \pm 0.08 \mathrm{~km} / \mathrm{sec}$ respectively. The standard deviations for depth were calculated using the normal error distribution methods.

\subsection{Models $\mathrm{B}_{2}$ and $\mathrm{B}_{2}$ (1974)}

Bhattacharya (1974) used the dispersion of Rayleigh and Love wave velocities in delineating the crust-upper mantle structure of the Indian Peninsula. He considered mainly two seismic profiles, one along Kodaikanal-New Delhi and the other along Kodaikanal and Poona. Some other profiles were also taken into consideration for a few earthquakes in the vicinity of New Delhi with Kodaikanal as the main recording station. The Rayleigh-wave periods range from $6-80 \mathrm{sec}$ whereas that for Love waves from $11-97 \mathrm{sec}$. The location of the seismological stations are shown in figure 1.

The crust-mantle seismic structure of the Central Peninsula and Western Ghats is shown by the velocity models $\mathrm{B}_{1}$. and $\mathrm{B}_{2}$ in figures $3 \mathrm{~A}, \mathrm{~B}$ respectively. Table 4 gives the variation of $P$-wave velocity with depth for these regions. In both the models, the granitic layer has been found quite thin as compared to the basaltic layer. These models reveal that the total crustal thickness in the central part of the peninsula is $41 \mathrm{~km}$ and increases to $52 \mathrm{~km}$ in the Western Ghats regions. S-wave seismic velocity

Table 3. P-wave velocity aistribution with depth for model KRN (1968)

\begin{tabular}{cr}
\hline $\begin{array}{c}\text { Depth below crust } \\
(\mathrm{km})\end{array}$ & $\begin{array}{c}P \text {-wave velocity } \\
(\mathrm{km} / \mathrm{sec})\end{array}$ \\
\hline 0 & $8 \cdot 31 \pm 0.02$ \\
$380 \pm 20$ & $9.47 \pm 0.06$ \\
$580 \pm 50$ & $10.15 \pm 0.07$ \\
$1000 \pm 120$ & $11.40 \pm 0.08$ \\
\hline
\end{tabular}


Table 4. $P$-wave velocity distribution with depth for models $B_{1}$ and $B_{2}$ (1974).

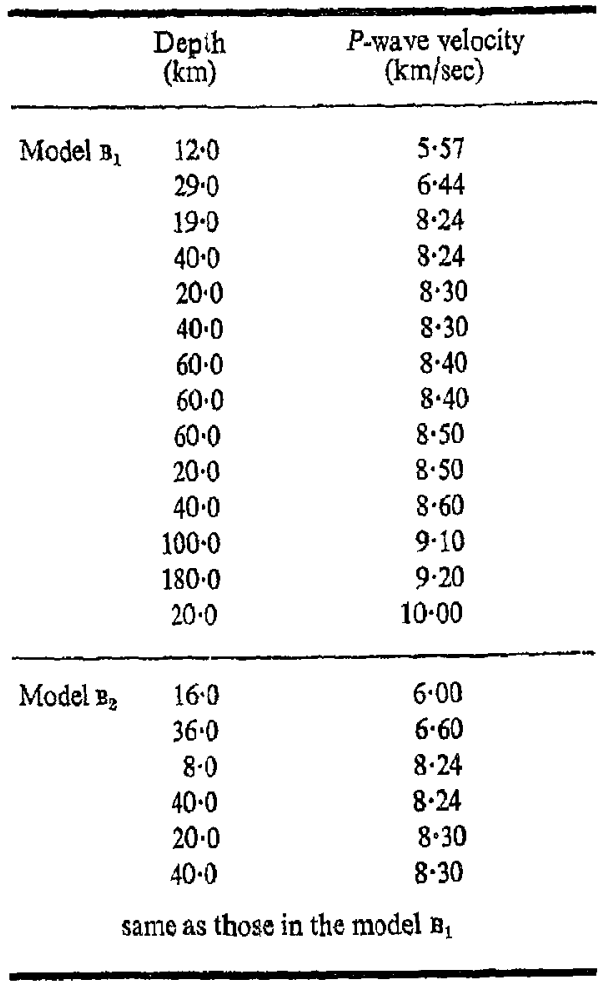
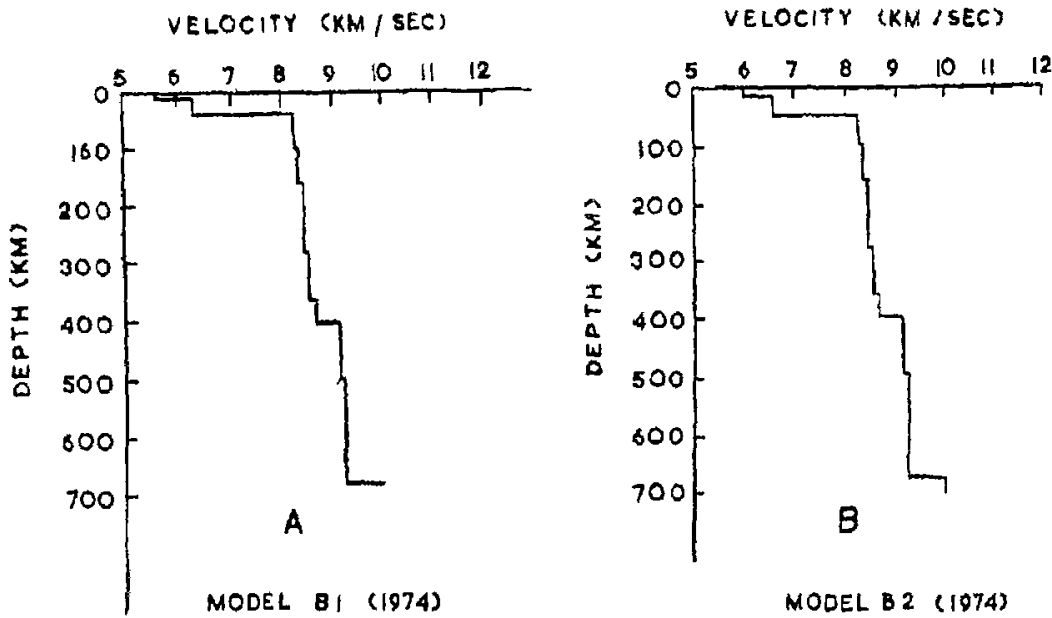

Figure 3. Upper mantle velocity models: (A) Model $B_{1}(1974)$ and (B) Model $B_{2}$ (1974), for central part of the Inaian Peninsula and Western Ghats respectively.

models have also been derived for these regions. Anisotropy has been found to occur between $60-160 \mathrm{~km}$ depth range in the central part of the peninsula on the basis of Rayleigh and Love wave data. There is a $5 \%$ decrease in SV wave velocity over $\mathrm{SH}$ velocity in this region. The upper mantle structure beneath $160 \mathrm{~km}$ depth remains the same for both the regions. 

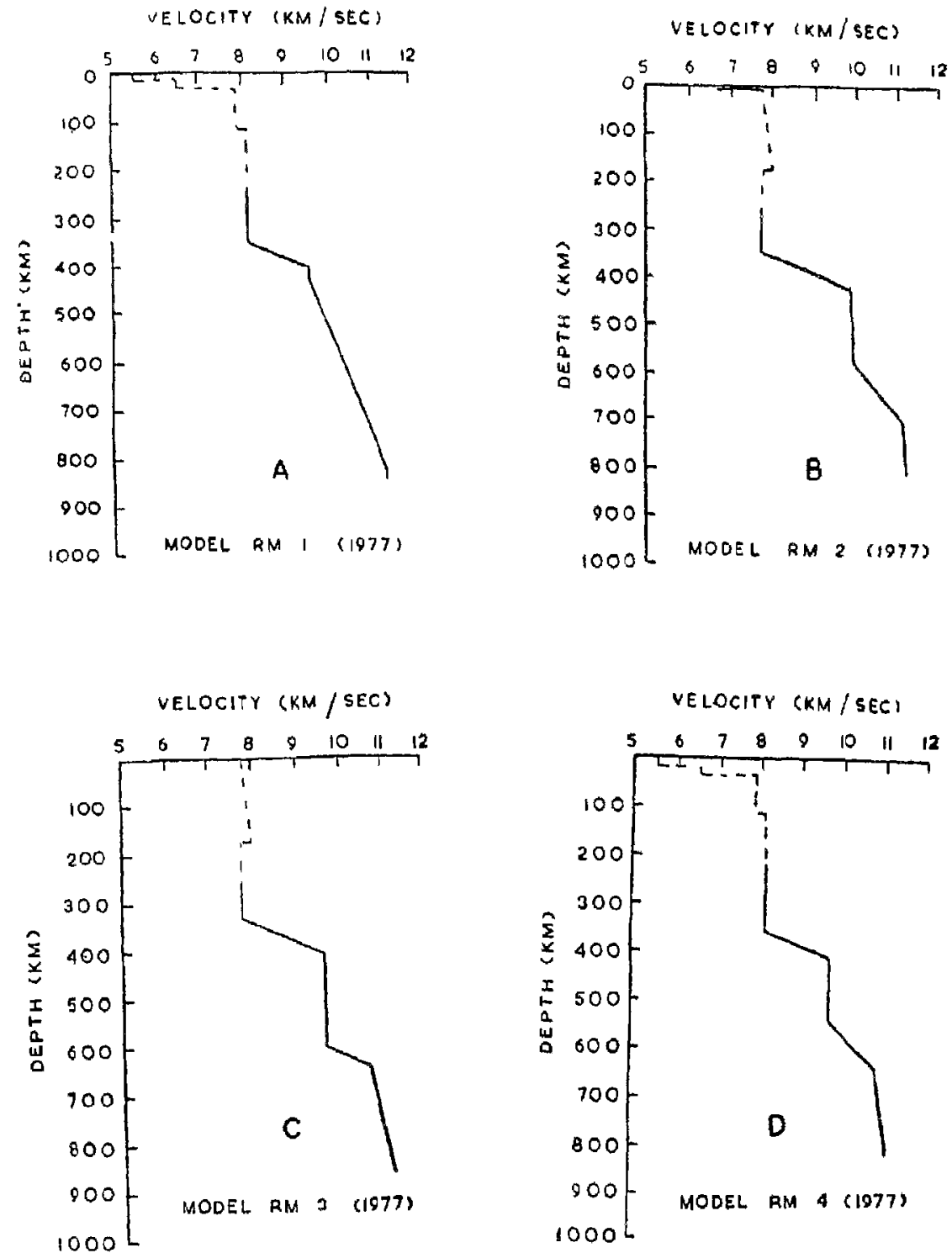

Figure 4. Upper mantle velocity models: (A) Model RMl (1977) and (D) Model RM4 (1977) are for the Indian subcontinent regions whereas (B) Model RM2 (1977) and (C) Model RM3 (1977) are for the Indian oceanic regions.

\subsection{Models RM (1977)}

Ram and Mereu (1977) derived four upper mantle velocity models for continental and oceanic regions using over 300 earthquakes recorded at Gauribidanur Seismic Array (GBA) in southern India. They applied adaptive processing filtering technique on the first $30 \mathrm{sec}$ of the short period $P$-wave signals in order to determine the slowness (slope of the travel-time curve) and apparent azimuths of the above events. They also tried to locate and identify the positions of the triplications on the upper mantle travel-time branches which are associated with the positive high velocity 
gradient zones or major phase discontinuities in the upper mantle. All velocity models were obtained by inverting the travel-time and slowness data using an iterative procedure and assuming the variation of velocity with depth in the form, $v=a r^{-b}$ where $v$ is the velocity at a radius $r$ and $a$ and $b$ are constants.

Models RM1 and RM4 are the continental velocity models. These were derived from earthquakes occurring in the Hinalayan and Hindukush regions respectively. The results reveal the seismic structure between sources and the receiver (GBA). These models are shown in figures $4 \mathrm{~A}, \mathrm{D}$ and the variation of $P$-wave velocity with depth is shown in table 5. The dotted portion of the models is the starting IB model (Jeffreys 1939). An abrupt change in the velocity was found near $400 \mathrm{~km}$ depth range for the above models. Similarly the evidence for large jump in velocity for model RM4 corresponding to ' $650 \mathrm{~km}$ ' depth range (discontinuity) has also been reported. However, in the case of model RMl, this discontinuity is replaced by a broad high velocity gradient zone, where a velocity depth structure much more consistent with the observed data has been found.

Table 5. F-wave velocities in continenta! and oceanic regions around India corresponding the models RMI (1977), RM4 (1977) and RM2 (1977), RM3 (1977) Tespectively.

\begin{tabular}{cc}
\hline $\begin{array}{c}\text { Depth } \\
(\mathrm{km})\end{array}$ & $\begin{array}{c}P \text {-wave velocity } \\
(\mathrm{km} / \mathrm{sec})\end{array}$ \\
\hline Model RML & (Himalayan region) \\
0 & $5 \cdot 50$ \\
15 & $5 \cdot 50$ \\
15 & $6 \cdot 50$ \\
33 & $6 \cdot 50$ \\
33 & $7 \cdot 90$ \\
113 & $7 \cdot 90$ \\
113 & $8 \cdot 13$ \\
354 & $8 \cdot 13$ \\
404 & $9 \cdot 55$ \\
434 & $9 \cdot 55$ \\
825 & 11.34 \\
847 & 11.34
\end{tabular}

\begin{tabular}{cc}
\hline $\begin{array}{c}\text { Depth } \\
(\mathrm{km})\end{array}$ & $\begin{array}{c}P \text {-wave velocity } \\
(\mathrm{km} / \mathrm{sec})\end{array}$ \\
\hline Model RM2 (Java & trench region) \\
0 & 5.07 \\
1 & 5.07 \\
1 & 6.70 \\
5 & 6.70 \\
5 & 7.80 \\
95 & 7.90 \\
175 & 8.00 \\
175 & 7.75 \\
352 & 7.75 \\
427 & 9.85 \\
574 & 9.85 \\
705 & $11 \cdot 08$ \\
725 & 11.08 \\
819 & 11.18 \\
Model RM3 (Mid-oceanic ridge) \\
0 & 5.07 \\
1 & 5.07 \\
1 & 6.70 \\
5 & 6.70 \\
5 & 7.80 \\
95 & 7.90 \\
175 & 8.00 \\
175 & 7.75 \\
332 & 7.75 \\
407 & 9.69 \\
599 & $9 \cdot 69$ \\
638 & 10.75 \\
860 & 11.29 \\
872 & 11.30 \\
& \\
\hline
\end{tabular}

\begin{tabular}{|c|c|c|c|}
\hline \multicolumn{2}{|c|}{ Model RM4 (Hjndukush region) } & \multicolumn{2}{|c|}{ Model RM3 (Mid-oceanic ridge) } \\
\hline 0 & $5 \cdot 50$ & 0 & $5 \cdot 07$ \\
\hline 15 & $5 \cdot 50$ & 1 & $5 \cdot 07$ \\
\hline 15 & 6.50 & 1 & $6 \cdot 70$ \\
\hline 33 & 6.50 & 5 & $6 \cdot 70$ \\
\hline 33 & $7 \cdot 90$ & 5 & $7 \cdot 80$ \\
\hline 113 & 7.90 & 95 & $7 \cdot 90$ \\
\hline 113 & $8 \cdot 13$ & 175 & $8 \cdot 00$ \\
\hline 362 & $8 \cdot 13$ & 175 & $7 \cdot 75$ \\
\hline 412 & $9 \cdot 67$ & 332 & 7.75 \\
\hline 545 & $9 \cdot 67$ & 407 & $9 \cdot 69$ \\
\hline 644 & $10 \cdot 84$ & 599 & $9 \cdot 69$ \\
\hline 678 & 10.84 & 638 & $10 \cdot 75$ \\
\hline 822 & $11 \cdot 12$ & 860 & 11.29 \\
\hline & & 872 & $11 \cdot 30$ \\
\hline
\end{tabular}


Velocity models $\mathrm{RM} 2$ and $\mathrm{RM} 3$ are the oceanic upper mantle models. These were derived from earthquakes occurring in the vicinity of Java trench region and MidIndian oceanic ridge. These models are shown in figures $4 \mathrm{~B}, \mathrm{C}$ and the variation of $P$-wave velocity with depth is given in table 5. A low velocity layer was introduced to satisfy the data before $20^{\circ}$ in these models. A large velocity jump near $400 \mathrm{~km}$ depth was required to account for the large variations in the slowness and travel-time measurements for both the models. The velocity increase associated with the ' $650 \mathrm{~km}^{\prime}$ discontinuity in the case of model RM2 is not sharp but certainly sharper than the broad velocity gradient zone found in the case of model RM1. However, in the case of model RM3, the velocity gradient corresponding with this discontinuity is relatively sharper than the other three models. An almost zero velocity gradient layer was introduced in the 450-650 km depth range to satisfy the amplitude observations.

Velocity models RMI, RM2, and RM4 satisfy most of the features observed, the problem of non-uniqueness of the interpretation of travel-time and slowness data was also examined in detail by Ram (1976). Tests were carried out in order to check the degree of confidence of these models. The travel-time branch positions, starting models used and velocity gradients were changed systematically and their effects on the thickness and depths of the transition zones as well as velocity were examined. Several multiple solutions for each of the models were obtained. Such results for model RM4 are illustrated in figures $5 \mathrm{~A}, \mathrm{~B}$. The maximum variation in the depths of the two discontinuities was $\pm 15 \mathrm{~km}$. The maximum uncertainty in the $P$-wave velocity distribution at a particular depth other than transition zones was approximately
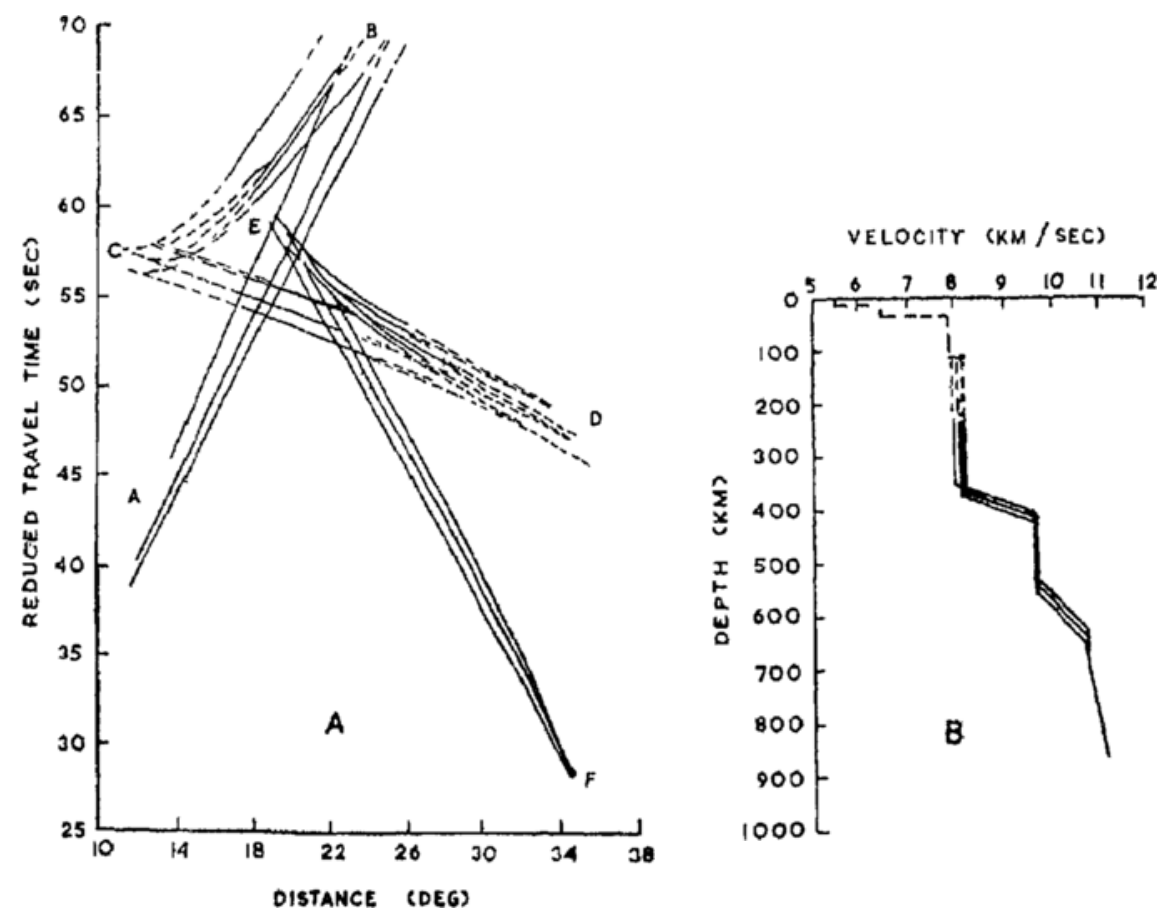

Flgure 5. (A) Various theoretical traveltime branches possible for tho velocity Medel RM4 (1977) and (B) the corresponding family of velocity models. 
$\pm 0.05 \mathrm{~km} / \mathrm{sec}$ whereas within the transition zones $\pm 0.15 \mathrm{~km} / \mathrm{sec}$. Similar effects were also observed if a low velocity layer was introduced in the dotted portion of the starting models (fgures 4 and 5). The error in the positioning of the various travel-time branches was also taken into consideration as $\pm 1 \mathrm{sec}$. However, the velocity profile did not show any significant change in this case either, as compared to the previous cases. The ray geometry for this model RM4 is illustrated in figure 6 . This represents the seismic structure and the path of the seismic rays followed between the source and the array.

\section{Chemical composition and state of upper mantle}

Several studies can be found in the literature on the geochemistry and mineralogy of the upper mantle regions. These studies showed that, in general, the factors such as partial melting, changes in pressure and temperature and mineralogical and chemical zonings can influence the observed changes in seismic velocities in the upper mantle. The phase transitions of the magnesium-rich olivine component into a $\beta$-spinel structure near $400 \mathrm{~km}$, into a $\nu$-spinel structure near $500 \mathrm{~km}$ and to a post-spinel phase near $600 \mathrm{~km}$ is probably responsible for the seismic velocity discontinuities or high positive velocity gradients found to exist at the corresponding depths (Ringwood, 1962, 1972; Ahrens 1973). Burdick and Anderson (1975) suggested that the ' $650 \mathrm{~km}$ ' discontinuity is due to the disproportion of $\boldsymbol{\nu}$-spinel to a mixture of magnesiowustitute $(\mathrm{Mg}, \mathrm{Fe}) \mathrm{O}$ and stishovite and, therefore, it is a chemical as well as phase boundary. However, the upper mantle of pyrolite composition with different proportions of minerals like olivine, pyroxenes and garnet have satisfied the seismic as well as experimental data. Anderson and Hart (1976) found the various transition zones to occur between depth ranges $375-425 \mathrm{~km}, 500-550 \mathrm{~km}$ and $650-675 \mathrm{~km}$ and at a moderate structure between $700-1200 \mathrm{~km}$ while satisfying the free oscillations and seismic body wave data.

\section{Discussion}

A large number of $P$-wave velocity models for upper mantle structure from different regions of the earth, in general, agree on the presence of the two major transition

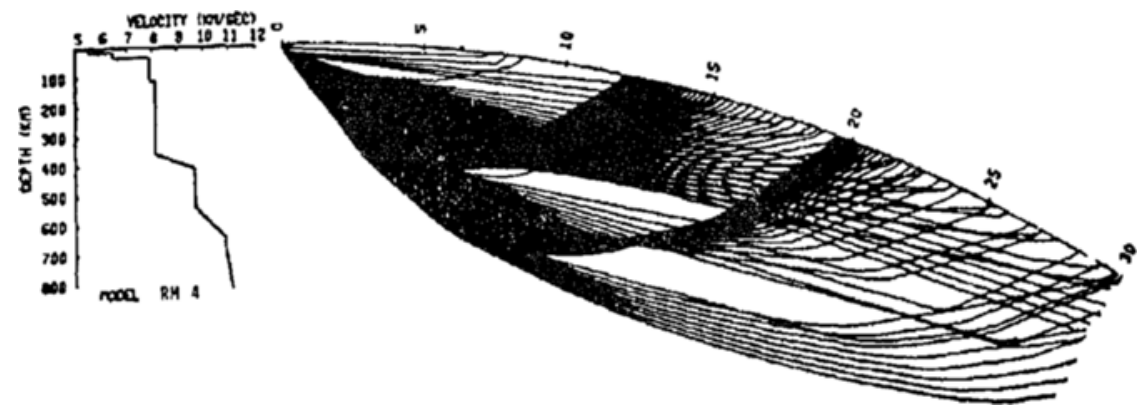

Figure 6. Ray geometry for the Model RM4 (1977). 
zones associated with ' $400 \mathrm{~km}$ ' and ' $650 \mathrm{~km}$ ' discontinuities. A few of them have shown the occurrence of high velocity gradients even below $700 \mathrm{~km}$ depth (Ram Datt and Muirhead 1976). The non-uniqueness in the velocity models can be attributed to the phenomenon like signal complexity and its variability (Douglas et al 1973), identification of the later arrivals and consequent positioning of the travel-time branches. About half a dozen upper mantle studies for Indian regions have been carried out in the past. Lukk and Nersesov (1965) have reported comparatively higher $P$-wave velocity for the Hindukush region. A low velocity layer was also found by them which occurs at $110-150 \mathrm{~km}$ depth range. Tandon (1967) has applied the Gutenberg's (1953) formula to derive velocity distribution of $P$-waves. He could not confirm the lack of observations between $12^{\circ}-15^{\circ}$ epicentral distance; whether this was due to the absence of observing stations at these distances or due to the existence of a shadow zone. Gutenberg's method is not suitable when there is a sudden decrease in the velocity. Moreover, this method is a graphical one and the apparent velocity near the point of inflexion depends very much on the slope of the curve drawn around the point of inflexion (which is difficult to locate). The derivation of low velocity channel by Tandon (1967) from $S$-wave data is based on this graphical technique which may not be fully justified as he has not found any evidence for

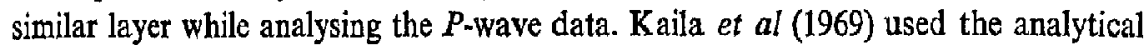
technique given by Kaila (1969) for the determination of $P$ and $S$-wave velocities in the upper mantle regions. In this method, the lower and upper limits of epicentral distance range are necessary so that a straight line within this range can be approximated. Hence, the ray parameter in the neighbourhood of the inflexion point is constant. This method was developed for deep focus earthquakes and may not be very suitable for shallow and intermediate focus events. Moreover, it is not applicable if there is an abrupt change in the variation of the seismic velocities. The accuracy of this technique is based on the number of observations within the distance range and it will deteriorate for very deep focus earthquakes as the number of observations from such events would be less. The standard deviations in velocity determination were found as $\pm 0.1 \mathrm{~km} / \mathrm{sec}$ which are based on statistical methods.

Model KRN (1968) has been derived by the method of weighting observations. This method takes into account all the observational points in least-square fitting but assigns little weight to those points having large deviations and hence they contribute very little to the process of least square fitting. This technique is unable to distinguish very minor changes in the slope of the travel-time curve as in most of the cases the data would be smoothed out and hence the model KRN (1968) does not reveal precise results about the velocity cistribution. The uncertainties in the depths of the discontinuities found by Kaila et al (1968) are large which in turn reflect upon the accuracy of the method of interpretation. Models $B_{I}$ and $B_{2}$ have been derived by Bhattacharya (1974) using dispersion of surface waves. He has found an evidence for anisotropy for $S$-waves in the depth range $60-160 \mathrm{~km}$ for the central part of the Indian peninsula. However, he did not mention such evidence for $P$-waves. Ram and Mereu (1977) have found very little evidence for anisotropy near the $500 \mathrm{~km}$ and $750 \mathrm{~km}$ depth ranges in the upper mantle of Indian regions while analysiing the data obtained from Gauribidanur seismic array.

Most of the upper mantle studies from the Indian subcontinent discussed in the preceding paragraphs have been confined to depths upto $300 \mathrm{~km}$. The detailed study 
by Ram and Mereu (1977) using short period $P$-wave array data is the first of its kind from continental as well as oceanic regions around the Indian subcontinent. Seismic arrays have got certain advantages over the single seismic station in that the slowness (or slope of the travel-time graph) can be measured directly from the observations, thus eliminating the need for smoothing and differentiating the travel-time curve. The direct measurement of the slope of the travel-time curve from the array data as a function of distance can then be used to invert the observations to obtain a velocity depth profle. Continental models (RML and RM4) and the oceanic models (RM2 and RM3) reveal significant variations in the upper mantle structure around India. Model RMl differs from the other three models in that the ${ }^{6} 650 \mathrm{~km}^{4}$ discontinuity is replaced by a very broad high velocity gradient zone and the velocity increases steadily below a depth of $450 \mathrm{~km}$. The nature of the abrupt change in velocity near $400 \mathrm{~km}$ is similar in models RM1 and RM4. However, this sudden jump in velocities at this depth is broader in the oceanic models. This may have been the result of the introduction of the low velocity zones in the upper portion of the models. The depths of the ' $650 \mathrm{~km}$ ' discontinuity in models RM2 and RM3 vary significantly. Although both the regions are the oceanic, the trenches and the mid-oceanic ridges are the results of two different tectonic processes. The former originates from the descending convection currents whereas the latter is from the rising currents prevailing in the upper mantle of the earth. The two oceanic models, RM2 and RM3, indicate the presence of a larger low $Q$ or low velocity layer along the oceanic paths as compared to the continental paths.

The upper mantle models for Hindukush region (Models LN (1965), $\mathrm{T}$ (1967) and KKN (1969)) do not show any consistency when compared with each other. The low velocity channel reported by Lukk and Nersesov (1965) has not been observed by Tandon (1967) and Kaila et al (1969). Similarly a positive high velocity gradient between $160-200 \mathrm{~km}$ depth range is not clearly evident in the case of model $\mathrm{kKN}$ (1969). Kaila et al (1969) observed higher seismic velocities for this region as compared to those for other regions of the earth. In the case of model RM4 (1977) for the Hindukush region, the observations before $15^{\circ}$ epicentral distance were not considered and as such cannot be compared with the above models. The velocity models KRN (1968) and RMI (1977) can be compared together as these have been derived from the events occurring in Himalayan and adjoining areas. The model RM1 (1977) shows slightly higher velocities near $400 \mathrm{~km}$ depth $(9.55 \mathrm{~km} / \mathrm{sec})$ and $825 \mathrm{~km}$ depth $(1 \mathrm{l} .34 \mathrm{~km} / \mathrm{sec})$ as compared to the model KRN (1968). It also differs in that ' $650 \mathrm{~km}$ ' discontinuity has been replaced by a broad high velocity gradient zone in the case of model RMI (1977) whereas this discontinuity bas been reported at $580 \pm$ $50 \mathrm{~km}$ by Kaila ef al (1968).

It is evident from the foregoing discussion that upper mantle seismic structure of Indian regions has significant lateral variations. Similar results have been reported for other continents also ( $\operatorname{Ram} 1979$ ). We are proposing a few intricate problems to be examined in detail in order to solve complicated problems of propagation of seismic waves in the Indian crust and upper mantle regions. Further study of fine structural variations in the crust and upper mantle would help in the better understanding of mechanism of earthquakes and movement of lithospheric plates:

-positioning of the cusps of travel-time branches associated with different discontinuities (sharpness of transition zones) as shown by Ram and Mereu (1977), whether there are indications of velocity discontinuities below the depth of 
$650 \mathrm{~km}$ in the Indian subcontinent as have been reported by Ram Datt and Muirhead (1976) using Australian array data,

-effect of scattering and attenuation on the propagation of seismic waves in the Indian crust upper mantle regions and complex seismic signatures observed in most of the cases may be resolved,

-inhomogeneity and anisotropy problems can be studied in detail for continental as well as Indian oceanic regions by installing suitable seismological stations net. works.

\section{Acknowledgements}

The authors thank Professor C L Singh for facilities. One of them (OPS) is also thankful to the Council of Scientific and Industrial Research (CSIR), New Delhi for financial assistance in the form of a fellowship.

\section{References}

Ahrens T J 1973 Phys. Earth Planet. Inter. 7167

Anderson D L and Hart R S 1976 J. Geophys. Res. 811461

Bhattacharya S N 1974 Geophys. J. R. Astron. Soc. 36273

Burdick L and Anderson D L 1975 J. Geophys. Res. 801070

Douglas A, Marshall P D, Gibbs P G, Young J B and Blamey C 1973 Geophys. J. R. Astron. Soc. 33195

Gutenberg B 1953 Bull. Seismol, Soc. Am. 43223

Jeffreys H 1939 Mon. Not. R. Astron. Soc. Geophys. Suppl. 4498

Kaila K L 1969 Bull. Seismol. Soc. Am. 59755

Kaila K L, Krishna V G and Narain H 1969 Bull. Seismol. Soc. Am. 591949

Kaila K L, Reddy P R and Narain H 1968 Bull. Seismol. Soc. Am. 581879

Lukk A A and Nerseso y I L 1965 Dokl. Akad. Nauk SSSR 16214

Ram A 1976 The identificatio $n$ and interpretation of upper mantle travel-time branches from slowness measurements made on data recorded at the Gauribidanur (India) and Yellow knife (Canada seismic arrays, Ph.D. Thesis, University of Western Ontario, London, Canada

Ram A 1979 Bull. Indian Soc. Earth Tech, 16153

Ram A and Mereu R F 1977 Geophys, J. R. Astron. Soc. 4987

Ram Datt and Muirhead K J 1976 Phys. Earth Planet. Inter. 1337

Ringwood A E 1962 J. Geophys. Res. 674005.

Ringwood A E 1972 Nature of the solld earth (ed) E C Robertson (New York: McGraw Hill) p. 677

Tandon A N 1967 India J. Met. Geophys. 18385 